\title{
Personalising the Learning Environment
}

\author{
Frank Kurzel, Jill Slay, and Kim Hagenus \\ University of South Australia, Adelaide, Australia
}

\section{Frank.Kurzel@unisa.edu.au Jill.Slay@unisa.edu.au Kim.Hagenus@unisa.edu.au}

\section{Abstract}

In this paper, we describe the development of a personalised multimedia/hypermedia learning environment that utilises multimedia presentation techniques in its interface while still providing Internet connectivity for management and delivery purposes. The structure of the domain is based on concepts that can be presented in a variety of ways; multimedia players display the content on the client computer. Tools are provided in the interface to allow students to search for concepts and create personalised views of the materials. Link annotations driven by an overlay student model are supported in all components of the system. The system supports the WWW as its addressing space but uses the local client areas to store media items expensive in terms of delivery time. Learning objects that provide frameworks for tasks and other summative assessment activities are stored on a server and delivered when required.

Keywords : Personalised Learning Environments, Adaptive Systems, Dynamic course generation, Student profiles, Learning Objects, Cognitive Flexibility Hypertext

\section{Introduction}

Computers have been used in the educational process since the early sixties with early applications generally improving in their ease of use and accommodation of more media rich items. The World Wide Web (WWW) has been introduced progressively into educational environments to support teaching. Typically, educational hypermedia/multimedia artefacts are now placed within some Learning Environment (LE) that is distributed over the WWW and accessible through some browser.

Maurer (Maurer, 2002) argues that even though the handling of different media items has improved over the years, the major improvements in LEs have come from other areas. The WWW for example, has provided us with a distribution infrastructure that overcomes distance and time, and hypertext/hypermedia environments provide associative access to educational materials. Embedded within these online educational materials have been multimedia artefacts that it has been proposed (Bonkhorst, 1998; Herrington \& Oliver, 1999; Looi \& Ang, 2000; Ricketts, Wolfe et al., 2000) enhance the educational process.

Jonassen et al (Jonassen, Peck et al., 1999) take the position that the true worth of multimedia and hypermedia might be obtained through the learner constructing knowledge via the use technology, rather than as a mode of delivery. Although there is agreement that the creation of multimedia and hypermedia artefacts is a powerful mechanism for individual learning, the learning benefits attributed to the con-

Material published as part of these proceedings, either on-line or in print, is copyrighted by Informing Science. Permission to make digital or paper copy of part or all of these works for personal or classroom use is granted without fee provided that the copies are not made or distributed for profit or commercial advantage AND that copies 1) bear this notice in full and 2) give the full citation on the first page. It is permissible to abstract these works so long as credit is given. To copy in all other cases or to republish or to post on a server or to redistribute to lists requires specific permission from the publisher at Publisher@InformingScience.org struction of different media views of content cannot be discounted; dual coding theory supports this assertion and recent experiments (Alty, 2002) indicate the significance of media in the presentation process.

Adaptive Hypermedia (AH) with its strong links to the Intelligent Tutoring Systems (ITS) field, utilise fine-grained hypermedia educational mod- 
ules with associative links to others. The further coupling of student and course models, has resulted in AH learning environments that provide the foundations of student centred work places. A number of universities are pursuing this development path in an attempt to provide managed, personalised learning environments for students.

A current view of a learning environment then, is a domain populated with instructional items, presented as either multimedia or hypermedia objects. The term object conforms to the IEEE Learning Technology Standards Committee specification (Committee, 2000) for learning objects; Wiley (Wiley, 2001) extends this interpretation to 'any digital resource that can be reused to support learning'.

There has however, been a growing concern among instructional designers that the metadata specification for the instructional significance of a learning object within the IEEE specification is inadequate. Wiley (Wiley, 2001) proposed a taxonomy for learning objects that was generic in the sense that it did not specify the role of the object in the instructional process.

Allert et al. (Allert, 2002) have proposed a top down framework with four levels of abstraction to define the pedagogical dimensions of each learning object. Each learning object may play different roles in the learning process, depending on the learning theory that it is used within.

This paper describes the on-going development of a prototype AMLE (Kurzel, 2002) proposed to test the proposition that multimedia and hypermedia based learning objects, encapsulated within some personalised student centred learning environment, has the potential to enhance the learning process, and consequently account for some individual student differences.

\section{The Learning Environment}

Some desirable characteristics of emerging LEs as suggested by Maurer (Maurer, 2002) include:

- re-usable content modules accompanied with searchable meta-data;

- a range of tools to create, combine and modify such modules into new ones;

- tools that allow the administration of the modules mentioned with statistical data gathered for authors, teachers, tutors and students as the system is used;

- a set of features for communication and collaboration including chat and discussion forums;

- facilities that allow the use of the system for various learning paradigms and different levels of learners,

- provision of a high degree of interactivity with powerful tools for (self) testing and feedback.

AMLE has been developed for the presentation of course material based upon AH systems. AH systems typically present content in fine-grained modules to enable the real-time allocation of learning objects to the learner and enable reusability. The content should be able to be structured or aggregated in different combinations to satisfy the requirements of the lecturer. A number also superimpose link annotations to provide the learner with relevant information about the modules based on what the system perceives the learner is ready for (information it has in a student profile), or from pre-requisite data stored in the course model. This addresses the problems associated with different entry knowledge and skills. (Figure 1.)

AMLE drives these annotations through its competency model. An assessment is made about whether a concept, be it knowledge based or practical in nature, is either known or can be performed. Online testing is used to cater for knowledge while demonstration may account for some practical tasks. Each concept carries a value for each student, reflecting this competency. The link to the concept is then annotated accordingly through either the colouring of the link using the traffic light metaphor (Weber, 1997) 


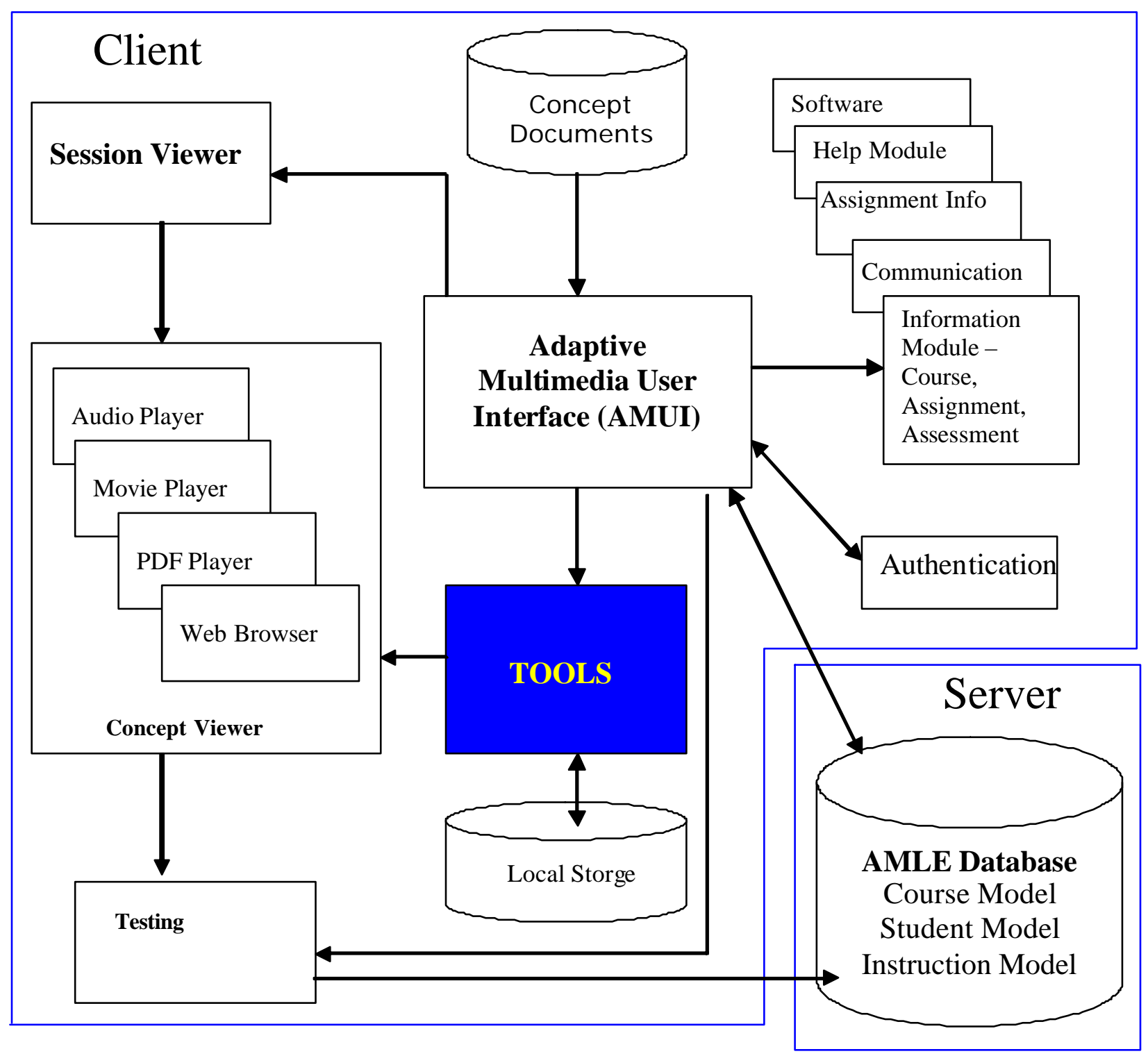

Figure 1: The AMLE System

(green, red, and amber), and by preceding the link with a visual cue $(+,-)$ for those with visual impairment. In this way, we are catering for students at different levels; however, links are not hidden, nor is there restricted access to any content.

A concept consists of a combination of documents (Pilar da Silvar, Van Durn et al., 1998) and downloaded data; this accounts for the content of a concept, its objectives, any pre-requisites, and assessment criteria; alternately, it might be an example of a task to be satisfied. There is a player associated with each item that displays the information in an appropriate manner. For example, the learning objectives of the concept are presented in a textual form within an additional window. An alternate presentation format might be audio. Players supporting this functionality are located with the client.

Further, some content is available in varying degrees of explanation to take account of different knowledge/skills. Stereotyping (Kay, 2000) employed within the student profile, provides a mechanism for the administration of content that varies in complexity. Web-based student access to these settings then pro- 
vides an adaptable (Oppermann, 1997) environment for students who wish to scrutinise and modify their settings.

A hybrid browser called a Session Viewer (Figure 2) initially presents the materials or concepts that would be covered in a week; in other words, the expert's view of the content on a weekly basis. The content can then be accessed sequentially; the concept structure of the course materials does not however necessitate that students access materials in this sequential manner.

We have a range of tools (search engine, glossary, course map) to enable the user to search the metadata and access concepts directly as required. As students become more familiar with the environment, the instructional strategies may vary.

The hypertext/hypermedia learning environment that we have created, allows the instructor to employ a range of instructional methodologies. Constructivist principles underpin the environment and students can actively involve themselves, creating items and placing them into their workspace or on the WWW, searching out content and skills, and satisfying authentic tasks. These are administered as required via the WWW as web pages. These in total, provide the macro level scaffolding (Bannan-Ritland, Dabbagh et al., 2001) that allow the students to use particular content in different, albeit overlapping, contexts. For example, more problem based learning activities could be introduced. These activities might relate to the construction of multimedia artefacts, the acquisition of some understanding, or the establishment of a reasoned point of view with regards some ethical is sue like copyright.

An on-line instructional management system has been constructed to establish courses based on concepts and sessions. We have an 'Administration Tool', which enables course coordinators to create particular courses and direct content at particular groups; we have the potential to administer concurrent versions. Lecturers and tutors have WWW access to our student model. Lecturers can add/delete a practical group, add a new student, search for existing student, and update student's detail such as practical, assignment and exam scores. Tutors have access to update and search facilities of students' practical and assignment details.

AMLE uses and maintains student profiles that contain a summary of the student's past experiences and other preference information. The course model and student profile allows students to proceed at their own rate through the learning environment; this access is influenced by a student's competencies and preferences. Further, the management system enables tutors to enter marks electronically and subsequently manage the assessment components of the course. Reporting mechanisms then cope with student, tutor and course co-ordinator requirements. (See Figure 3.) 


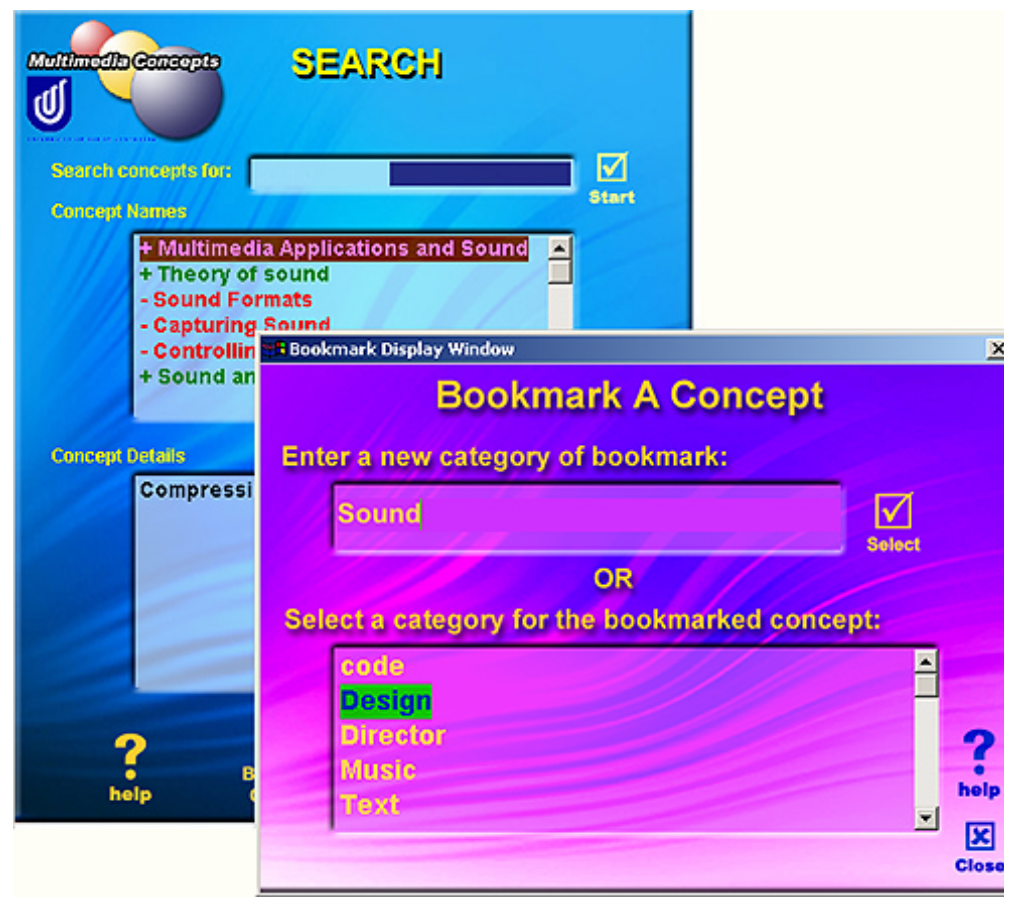

Figure 3: Searching and book marking

Communications will involve student/student and lecturer/tutor/student interactions via online discussion groups that will support collaborative and/or group learning. These could be practical discussion groups with a number of their peers currently logged on addressing some weekly task. Alternatively, they might be one-on-one interactions with the tutor or lecturer.

\section{Instructional Design}

In its basic format, the semantic network of concepts grouped into sessions based on the expert's view, provides individual concepts providing facts and related practical techniques. Mullier inserted tutorials into the semantic network making up Hypernet (Mullier \& Dixon, 2000) to provide the students with tutorial tasks to reinforce learning. JointZone (C) $(\mathrm{Ng}, 2002)$ utilises both declarative and procedural knowledge in a hypermedia learning that provides adaptive case studies to medical students.

To provide for other instructional methodologies within the course model, we administer through the WWW, other instructional pieces that may require competence with a number of concepts. The concepts then are addressed within extended learning activities that again might handle a week's worth of work for example. Further, some activities that correspond to more summative assessments that may involve larger groupings of concepts and the demonstration of other higher level skills e.g. ability to represent a design, communicate information, etc., are coordinated through on- line templates/documents that become available when required.

We might for example, want to introduce the topic of Sound in Multimedia to students with the practical task being to create an MP3 player. Areas to be addressed could include:

- the possible application of sound in multimedia applications;

- theory of sound - representation, capturing, etc;

- $\quad$ sound formats - compression, filetypes, size etc. 
- $\quad$ sound capture;

- sound control within multimedia applications;

- ethical considerations re: copyright etc.

Lecturers might choose to cover these topics in a structured way, or alternately, might set them up as a project and allow students to search out the information from the semantic network of concepts. To this end, students need tools to help in this process, along with instructions and/or templates to assist them. AMLE uses a book marking facility that is accessible in all the direct access tools to allow the construction of personalized groupings of concepts.

These groupings don't necessarily need to be directly related to assessable activities; they might simply be the individual goals for a student's personal investigation. The end result as suggested by Jonassen and schema theory (Eklund, 1995), is a fine grained network of connected concepts that are accessed, accumulated, and organised personally by the student and then restructured as coarser-grained schemas. Multiple views and groupings in a range of educational activities then is a partial realisation of an environment supporting cognitive flexibility theory (Spiro, 1987).

The dynamically generated course maps provided in the interface graphically represent persistent (although editable) views of concepts from both the students' and experts' perspectives. The coloured annotations are extended to these graphical representations. This structure then provides a mechanism for the provision of other learning paradigms, the documentation of which exists within the course profile and available over the WWW.

\section{Conclusion}

The current work has involved the creation of provisions within the environment to provide for more student-centred activities. We have provided tools and representations to allow students to break away from the expert view and follow personalised goals. In particular, a book marking capability has been embedded into the system components to provide for individual and editable groupings of concepts that still drive the main components of the system e.g. the concept viewer.

Future work will investigate further moves towards a cognitive flexibility hypertext where multiple views of the course content are provided. The student profiling information will allow indexing capabilities and the further personalisation of the environment.

The problems associated with working on and off line need to be addressed; some media rich artefacts which are stored locally, should still be accessible when not on-line. These protocols need to be addressed to allow students to store items locally but still be included in their global workspace.

\section{References}

Allert, H., Dhraief, H, Nejdl, W. (2002). Meta-Level category 'Role' in metadata standards for learning: Instructional roles and instructional qualities of learning objects.

Alty, J. L. (2002). Dual coding theory and computer education: Some media experiments to examine the effects of diffe rent media on learning. ED-MEDIA, Dever, Colorado, AACE.

Bannan-Ritland, B., N. Dabbagh, et al. (2001). Learning object systems as constructivist learning environments: Related Assumptions, theories and applications. The Instructional Use of Learning Objects. D. A. Wiley. Bloomington, IN, Association for Educational Communications and Technology.

Bonkhorst, J. (1998). The use of multimedia learning environments in teacher training colleges. ATEE, Limerick, Ireland.

Committee, I. L. (2000). Learning objects metadata draft v4.1.

Eklund, J. (1995). Cognitive models for structuring hypermedia and implications for learning from the world-wide web. AUSWEB, Ballina, NSW. 
Herrington, J. and R. Oliver (1999). Using situated learning and multimedia to investigate higher-order thinking. Journal of Interactive Learning Research 10(1): 3-24.

Jonassen, D., K. L. Peck, et al. (1999). Learning with technology: A constructivist perspective. Upper Saddle, NJ, Merrill, Prentice Hall.

Kay, J. (2000). Stereotypes, student models and scrutability. ITS2000, Montreal, Canada, Springer-Verlag.

Kurzel, F., Slay, J. \& Chau, Y (2002). Towards an adaptive multimedia learning environment. InSITE2002, Cork, Ireland, AACE.

Looi, C. K. and D. Ang (2000). A multimedia-enhanced collaborative learning environment. Journal of Computer Assisted Learning 16: 2-13.

Maurer, H. (2002). What have we learnt in 15 years about educational multimedia . ED-MEDIA 2002, Denver, Colorado, AACE.

Mullier, J. L. and M. B. Dixon (2000). Authoring educational hypermedia using a semantic network. ED-MEDIA 2000, Montreal, Canada, AACE.

Ng, M. H., Maier, P. and Hall, W. (2002). Making web-based learning adaptive. InSITE2002, Cork, Ireland, AACE.

Oppermann, R., Rashev, R. \& Kinshuk (1997). Adaptability and adaptivity in learning systems . Knowledge Transfer. A. Behrooz. London, UK, pAce. 11: 173-179.

Pilar da Silvar, D., R. Van Durn, et al. (1998). Concepts and documents for adaptive educational hypermedia: a model and a prototype. 2nd Workshop on Adaptive Hypertext and Hypermedia, HYPERTEXT'98, Pittsburgh, USA.

Ricketts, J., F. H. Wolfe, et al. (2000). Multi-media - Asynchronous distributed education. Social Science Computer Review 18(2): 132-146.

Spiro, R. J., Feltovich, P. J., Jacobson, M. J., \& Coulson, R. L. (1987). Cognitive flexibility constructivism and hypertext: Random access instruction for advance knowledge acquisition in ill-structured domains. Constructivism and the Technology of Instruction: A Conversation. T. J. Duffy, D. Englewood Cliffs, NJ, Lawrence Erlbaum Associates.

Weber, G. a. S., M. (1997). User modeling and adapative navigation support in WWW-based tutoring systems . User Modeling, Calliari, Italy.

Wiley, D. A., II (2001). Connecting learning objects to instructional design theory: A definition, a metaphor, and a taxonomy. The Instructional Use of Learning Objects. D. A. Wiley. Bloomington, IN, Association for Educational Communications and Technology.

\section{Biographies}

Frank Kurzel is a lecturer in the School of Communication, Information and New Media of the University of South Australia. He has been the Program Director for the Multimedia Studies Major within the Bachelor of Arts program at the University of South Australia. He has had extensive experience in Education, Computer Science and Multimedia areas.

His research interests include web-based instructional systems to support his teaching, and the integration of Intelligent Tutoring Systems technology into hypermedia environments. He is also interested in instructional methodologies and enhancing the educational environment.

Jill Slay is a Senior Lecturer in the School of Computer and Information Science of the University of South Australia. She is currently Director of International Programs within the school and manages the Offshore programs taught in Hong Kong and Malaysia. She has an interest in IT security education, and is publishing in this area as well as in information war-fare and more generally within complex sociotechnical information systems, particularly C2 systems. She is also carrying out research in e-commerce and adaptive web-based multimedia systems and supervising research in the technical and pedagogical design of online and multimedia learning environments. She leads the cross-disciplinary Technology in Higher Education Research Group and also works within the Advanced Computing Research Centre and the Systems Engineering and Evaluation Centre. Currently she is Deputy Chair of the University 
Women's Consultative Committee and co-chair of the Division of IEE Equity Committee and as such is a member of the Division of IEE executive.

Kim Hagenus is a recent honours graduate from the Computing and Multimedia degree offered by the School of Computer and Information Science at the University of South Australia, Australia. She has an interest in adaptive hypermedia and multimedia and is currently a researcher for the Technology in Higher Education Research Group (THERG). She also tutors within the undergraduate multimedia programs conducted at the University of South Australia. 